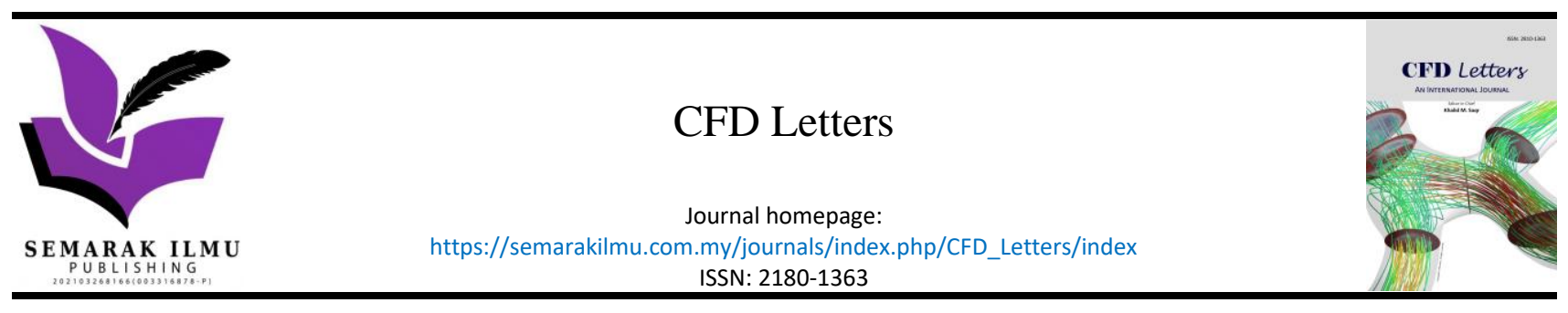

\title{
The Influences of Oxygen Concentration and External Heating on Carbon Nanotube Growth in Diffusion Flame
}

\author{
Lei $\mathrm{Li}^{1,2}$, Muhammad Thalhah Zainal ${ }^{1,2}$, Mohd Fairus Mohd Yasin ${ }^{1,2^{*}}$, Norikhwan Hamzah ${ }^{1,2}$, Mohsin \\ Mohd Sies ${ }^{1,2}$, Muhammad Noor Afiq Witri Muhammad Yazid², Shokri Amzin³ ${ }^{3}$ Aizuddin Supee ${ }^{4}$ \\ 1 High Speed Reacting Flow Laboratory (HIREF), School of Mechanical Engineering, Faculty of Engineering, Universiti Teknologi Malaysia, 81310 \\ Skudai, Johor, Malaysia \\ School of Mechanical Engineering, Universiti Teknologi Malaysia, 81310 Skudai, Johor, Malaysia \\ 3 Department of Marine and Mechanical Engineering, Western Norway University of Applied Sciences, Bergen, Norway \\ 4 Energy Management Group, School of Chemical and Energy Engineering, Faculty of Engineering, Universiti Teknologi Malaysia, 81310 Skudai, \\ Johor, Malaysia
}

\section{ARTICLE INFO}

\section{Article history:}

Received 14 June 2021

Received in revised form 25 October 2021

Accepted 27 October 2021

Available online 14 December 2021

\section{Keywords:}

Flame synthesis; carbon nanotube (CNT); flame structure; multi-scale model; computational fluid dynamics (CFD); growth rate model

\section{ABSTRACT}

Tight control of the carbon nanotube (CNT) synthesis process in flames remains a challenge due to the highly non-uniform gradient of flame thermochemical properties. The present study aims to establish a baseline model for flame-enhanced chemical vapor deposition (FECVD) synthesis of CNT and to analyze the CNT growth region at varying flame and furnace conditions. The numerical model comprises a computational fluid dynamics (CFD) simulation that is coupled with the CNT growth rate model to simulate the flow field within the furnace and the CNT growth respectively. Validation of the flame shape, flame length, and temperature profile are carried with a reasonable comparison to experimental measurements. A parametric study on the effects of furnace heating capacity and oxidizer concentration is conducted. The results of the CNT growth rate model reveal that there is a positive correlation between the heater power and CNT length. Supplying a higher concentration oxidizer at a fixed furnace power is predicted to result in further improvement in CNT length and high yield region. Flame structure analysis showed that with the heater turned on at $750 \mathrm{~W}$ (corresponding to heat flux of $21,713 \mathrm{~W} / \mathrm{m}^{2}$ ), the growth region expands twofold when oxygen concentration is increased from $19 \%$ to $24 \%$. However, the growth region shrinks when the oxygen concentration is further increased to $27 \%$ which indicates depletion of carbon source for CNT growth due to excess oxygen. The finding of this research could guide and optimize the experiment of the flame-assisted CNT production in the future.

\section{Introduction}

Carbon nanotube (CNT) is a nanomaterial that is desired in various application like nanofluid, composite fillers, and electronics devices due to the excellent mechanical, thermal, and electrical properties of CNT [1,2]. Currently, the chemical vapour deposition (CVD) is the most popular method

\footnotetext{
* Corresponding author.

E-mail address: mohdfairus@mail.fkm.utm.my (Mohd Fairus Mohd Yasin)
}

https://doi.org/10.37934/cfdl.13.12.4562 
for the mass production of CNT $[3,4]$. However, the slow process and high energy consumption of CVD synthesis result in high production cost. To alleviate the cost associated with the mass production of CNT, the flame-enhanced CVD (FECVD) technique is introduced. CNT growth in a flameassisted environment is a multi-scale phenomenon that involves flame scale and particle scale computations. However, the previous studies of modeling flame-assisted CNT production focused mainly on the combustion side, without including CNT growth simulation at the particle level $[5,6]$. CNT growth region within the flame was not explicitly modelled because of the lack of a particle scale model to capture CNT growth.

To fulfill the multi-scale nature of CNT growth, a coupled model that integrates computational fluid dynamics (CFD) with particle scale model to predict material growth is needed. Zainal et al., [6] proposed a coupled model that combined flame simulation with a CNT growth rate model to estimate CNT length and growth region. The proposed model improved the CNT growth rate model developed earlier that was principally catered for CNT growth in a CVD furnace [7]. Based on the diesel engine's CNT production experiment, Suzuki and Mori [8] modeled the CNT growth rate by considering CO, ethylene, and acetylene as the sources of carbon deposition. Hamzah et al., [9] adopted a multi-scale model by integrating CFD simulation and particle level prediction to estimate the CNT growth region in a normal diffusion flame.

Despite the attractive feature of the flame synthesis technique such as high growth rate, auto thermal process, and co-generation of heat and carbon source, controlling CNT growth in a flame environment remains a challenge due to complex interaction between flame temperature and species concentrations [2]. The CNT growth region is limited due to competition with other byproducts like soot [10]. The flame structure is a useful tool to integrate flame temperature, species concentration, and growth region of combustion products. In a flame structure, the flame temperature and species concentration are linked by the mixture fraction, utilized to identify the potential CNT growth region. A previous study employed a flame structure analysis to describe the CNT growth region in inverse diffusion flame with methane and ethylene gas mixture as the fuel source [11]. However, only a few studies relate the flame structure with CNT production [12-14].

One of the control parameters in diffusion flame synthesis is the inlet oxygen concentration. Previous flame synthesis experiments showed that an increase in inlet oxygen concentration improves CNT growth $[15,16]$. A previous study pointed out that an increase in oxygen concentration provides more combustion and thus larger high temperature region [11]. In relation to this, Zhang et al., [17] mentioned that availability of abundant high temperature within the flame results in CNT with better quality and improved yield. However, a recent study demonstrated that there exists a limit to the oxygen concentration where too high of oxygen concentration can result in reduced CNT yield and growth rate [18]. In the study, an increase of oxygen concentration from $15 \%$ to $30 \%$ resulted in maximized CNT growth but further increasing the oxygen to $40 \%$ caused a narrowing trend of CNT growth region [18]. From the brief review above on the control parameters for flame synthesis such as the flame structure and oxygen concentration, it can be inferred that majority of the investigation was done for flame synthesis configuration. Similar studies on the hybrid flame-CVD setup are hardly available in the open literature and are deemed necessary for optimization of FECVD systems.

Furthermore, the published CFD modeling and relevant experimental investigations have not included a detailed study of the influence of external heat source on CNT growth $[9,11]$. In the present study, a thorough validation of the coupled CFD-growth rate model computation will first be carried out. Then, the effects of external heater and different inlet oxygen concentrations on CNT growth will be discussed. 


\section{Experimental Conditions and Numerical Models}

\subsection{Experimental Conditions}

The present modeling study is based on the flame synthesis experiment work by Hamzah where a methane diffusion flame is employed [19]. The CFD simulation is carried out for multiple operating conditions of a standing flame. For each case, a wire mesh geometry is integrated within the simulation domain at $13 \mathrm{~mm}$ height above burner (HAB) to mimic the placement of wire mesh substrate inside the flame during the flame synthesis experiment. Previous study neglects the presence of wire mesh insertion into the flame with the assumption of negligible effects toward the flame flow field [11]. However, the same assumption cannot be applied in the present study as the wire mesh employed in the experiment significantly alters the flame shape. A fixed $H A B$ of $13 \mathrm{~mm}$ is chosen in the present study to ensure the ensuing parametric study is not affected by the HAB. In the present work, inlet conditions that include the concentration of fuel and oxidizer are varied. The fuel stream $\mathrm{CH}_{4}$ and the oxidizer stream $\left(\mathrm{O}_{2}+\mathrm{N}_{2}\right)$ are kept at 0.4 standard liter per minute (s/pm) and 3.7 slpm, respectively, with the condition of $20^{\circ} \mathrm{C}$ and $1 \mathrm{~atm}$.

\subsection{Numerical Simulation}

\subsubsection{Governing equations}

The continuity and momentum equations shown in Eq. (1) and Eq. (2), respectively, are solved along with the flamelet equations that solve for temperature $T$ and species $Y_{k}$ as shown in Eq. (3) and (4), respectively. The flamelet approach is employed in the present study due to the faster computational time of solving detailed chemistry compared to the conventional solver [20]. Variables $\rho, u_{j}$, and $x_{j}$ in Eq. (1) are the fluid density, velocity component, and the cartesian direction, respectively whereas $p$ and $\mu$ denote in Eq. (2) denote the pressure and laminar viscosity, respectively. Variables $x, z, c_{p}, h_{k}$, and $\dot{\omega}_{k}$ in the flamelet governing equations are the scalar dissipation rate, mixture fraction, specific heat capacity, specific enthalpy of species $k$, and the chemical source term, respectively.

$\frac{\partial \rho}{\partial t}+\frac{\partial\left(\rho \mathrm{u}_{\mathrm{j}}\right)}{\partial \mathrm{x}_{\mathrm{j}}}=0$

$\frac{\partial \rho \mathrm{u}_{\mathrm{i}}}{\partial \mathrm{t}}+\frac{\left(\partial \rho \mathrm{u}_{\mathrm{i}} \mathrm{u}_{\mathrm{j}}\right)}{\partial \mathrm{x}_{\mathrm{j}}}=-\frac{\partial \mathrm{p}}{\partial \mathrm{x}_{\mathrm{i}}}+\frac{\partial}{\partial \mathrm{x}_{\mathrm{j}}}\left[\mu\left(\frac{\partial \mathrm{u}_{\mathrm{i}}}{\partial \mathrm{x}_{\mathrm{j}}}+\frac{\partial \mathrm{u}_{\mathrm{j}}}{\partial \mathrm{x}_{\mathrm{i}}}-\frac{2}{3} \delta_{\mathrm{ij}} \frac{\partial \mathrm{u}_{\mathrm{k}}}{\partial \mathrm{x}_{\mathrm{k}}}\right)\right], \mathrm{i}=1,2,3$

$\frac{\rho \partial Y_{k}}{\partial t}=\rho \frac{1}{2} x \frac{\partial^{2} Y_{k}}{\partial z^{2}}+\dot{\omega}_{k}$

$\frac{\rho \partial T}{\partial t}=\rho \frac{1}{2} x\left(\frac{\partial^{2} T}{\partial z^{2}}+\frac{1}{c_{p}} \frac{\partial c_{p}}{\partial z} \frac{\partial T}{\partial z}\right)-\frac{1}{c_{p}} \sum_{k=1}^{n} h_{k} \dot{\omega}_{k}$

\subsubsection{Turbulence model}

The pressure-based concept is suitable for low Mach number flows without considering fluid's density variation. On the strength of its robustness, effectiveness, less dependency on equipment and reasonable application accuracy standard $k-\varepsilon$ turbulence model has become most popular in practical engineering flow calculations. Transport equations as shown in Eq. (5) and Eq. (6) are applied to calculate the turbulence kinetic energy $k$ and the rate of dissipation $\varepsilon$. The source term $S_{k}$ includes 
turbulence kinetic energy from mean velocity gradients, buoyancy, fluctuating dilatation in compressible turbulence, user-defined source term. $C_{1 \varepsilon}, C_{2 \varepsilon}$, and $C_{3 \varepsilon}$ are the turbulent model constants.

$$
\begin{aligned}
& \frac{\partial}{\partial \mathrm{t}}(\rho \mathrm{k})+\frac{\partial}{\partial \mathrm{x}_{\mathrm{i}}}\left(\rho \mathrm{ku}_{\mathrm{i}}\right)=\frac{\partial}{\partial \mathrm{x}_{\mathrm{j}}}\left[\left(\mu+\frac{\mu_{\mathrm{t}}}{\sigma_{\mathrm{k}}}\right) \frac{\partial \mathrm{k}}{\partial \mathrm{x}_{\mathrm{j}}}\right]+\mathrm{S}_{\mathrm{k}} \\
& \frac{\partial}{\partial \mathrm{t}}(\rho \varepsilon)+\frac{\partial}{\partial \mathrm{x}_{\mathrm{i}}}\left(\rho \varepsilon \mathrm{u}_{\mathrm{i}}\right)=\frac{\partial}{\partial \mathrm{x}_{\mathrm{j}}}\left[\left(\mu+\frac{\mu_{\mathrm{t}}}{\sigma_{\varepsilon}}\right) \frac{\partial \varepsilon}{\partial \mathrm{x}_{\mathrm{j}}}\right]+\mathrm{C}_{1 \varepsilon} \frac{\varepsilon}{\mathrm{k}}\left(\mathrm{G}_{\mathrm{k}}+\mathrm{C}_{3 \varepsilon} \mathrm{G}_{\mathrm{b}}\right)-\mathrm{C}_{2 \varepsilon} \rho \frac{\varepsilon^{2}}{\mathrm{k}}+\mathrm{S}_{\varepsilon}
\end{aligned}
$$

\subsubsection{Finite-Rate chemistry model}

In chemistry model, the variables of chemical species could be solved conservation equations with convection, diffusion, and reaction terms. The rate of gas-phase reactions is defined on a volumetric foundation and species conservation equations treat the changing rate of chemical species as a source term. The process of adsorption and desorption in surface reactions are controlled by both chemical kinetics and diffusion to and from the surface. And this process can be applied to the simulation of CVD. Finite-rate chemistry includes volumetric reactions, wall surface reactions and particle surface reactions. In the present study, the chemical equilibrium assumption is employed and then the species mass fraction will be determined by the mixture fraction, including the influence of intermediate species and dissociation reactions.

\subsection{Computational Domain and Boundary Conditions}

The CFD model of this flame-assisted synthesis is a steady simulation of a two-dimensional axisymmetric geometry as shown in Figure 1 . The size of the combustion area is $38.5 \mathrm{~mm} \times 60 \mathrm{~mm}$ with an upstream section of about $150 \mathrm{~mm}$ long, a wire mesh section, and a downstream region. To capture the flow through the wire mesh section, denser cells are specified in the simulation domain near the wire mesh geometry. Therefore, the meshing of the geometry is generated in a fashion that the number of cells between the gaps of wire mesh would have about 5-10 cells. The grid independence test was done for four mesh grades ranging from 13,000 cells to 104,000 cells.

The general boundary condition that applies to all CFD simulation in the present study is presented in Table 1. Settings for a case setup such as the turbulence model, radiation model, and species model are also described in Table 1. Specific boundary conditions for the simulation of various standing flames with their respective flame numbering are listed in Table 2 . Finally, the wall boundary condition for the simulation of FECVD furnace with heater is described in Table 3 . The heat flux $q$ in Table 3 is calculated using Eq. (7) where $P$ is the furnace power and $S$ the wall surface area.

$q=P / S$

The simulation domain is discretized by the second-order upwind scheme for spatial discretization of momentum, energy, mixture fraction, turbulent kinetic energy, and turbulent dissipation rate. Also, the Green-Gauss cell-based and the second-order discretization schemes are employed for gradient and pressure, respectively. 


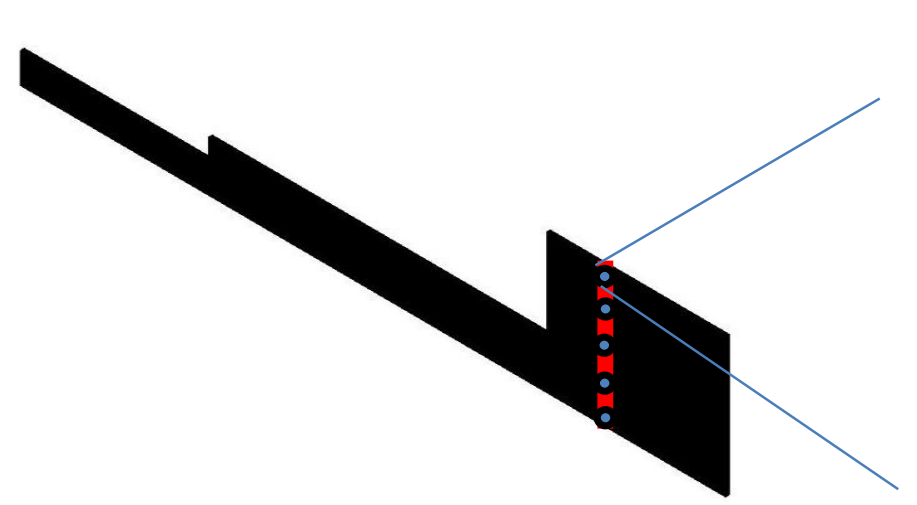

(a)

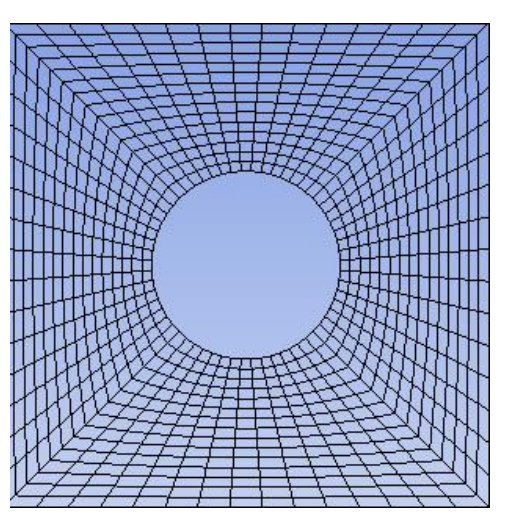

(b)

Fig. 1. Computational domain; (a) Ultra-fine mesh of entire simulation domain with schematic of wire mesh in red. Combustion gas flows from left to right.; (b) enlarged wire mesh section

Table 1

Simulation models and general boundary conditions for CFD simulation

\begin{tabular}{llll}
\hline $\begin{array}{l}\text { Simulation models and } \\
\text { boundary conditions }\end{array}$ & Type & Value & Unit \\
\hline Turbulence model & Standard $k-\varepsilon$ & - & - \\
Near wall treatment & Standard wall & - & - \\
& function & & \\
Radiation model & P1 & - & - \\
Species model & Non-premixed & - & - \\
Fuel inlet & Velocity inlet & 0.03 & $\mathrm{~m} / \mathrm{s}$ \\
Oxidiser inlet & Velocity inlet & 0.21 & $\mathrm{~m} / \mathrm{s}$ \\
Wire mesh & Heat flux & 0 & $\mathrm{~W} / \mathrm{m}^{2}$ \\
Outlet & Pressure outlet & 0 (relative pressure) & $\mathrm{Pa}$ \\
\hline
\end{tabular}

\section{Table 2}

Specific boundary conditions of the simulated standing flames without heater based on Hamzah [19]

\begin{tabular}{|c|c|c|c|c|c|}
\hline \multirow{2}{*}{$\begin{array}{l}\text { Flame } \\
\text { numbering }\end{array}$} & \multicolumn{2}{|c|}{ Fuel component (\% vol) } & \multicolumn{2}{|c|}{ Oxidizer component (\% vol) } & \multirow[t]{2}{*}{$z_{s t}$} \\
\hline & $\begin{array}{l}\text { Methane conc. } \\
\text { (\%vol) }\end{array}$ & $\begin{array}{l}\text { Nitrogen conc. } \\
\text { (\%vol) }\end{array}$ & $\begin{array}{l}\text { Oxygen conc. } \\
\text { (\%vol) }\end{array}$ & $\begin{array}{l}\text { Nitrogen conc. } \\
\text { (\%vol) }\end{array}$ & \\
\hline Flame1AWo & 100 & 0 & 19 & 81 & 0.05 \\
\hline Flame1BWo & 100 & 0 & 21 & 79 & 0.055 \\
\hline Flame1CWo & 100 & 0 & 24 & 76 & 0.0625 \\
\hline Flame1DWo & 100 & 0 & 27 & 73 & 0.0691 \\
\hline Flame3AWo & 50 & 50 & 19 & 81 & 0.0678 \\
\hline Flame3BWo & 50 & 50 & 21 & 79 & 0.074 \\
\hline Flame3CWo & 50 & 50 & 24 & 76 & 0.083 \\
\hline Flame3DWo & 50 & 50 & 27 & 73 & 0.0927 \\
\hline
\end{tabular}

Table 3

Heat flux wall boundary condition for flame simulation with heated furnace

\begin{tabular}{lll}
\hline Flame & Heat flux $\left(\mathrm{W} / \mathrm{m}^{2}\right)$ & Remark \\
\hline Flame1B_0 & 0 & Without furnace \\
Flame1B_100F & 100 & With furnace \\
Flame1B_2000F & 2000 & With furnace \\
Flame1B_10000F & 10000 & With furnace \\
Flame1B_15000F & 15000 & With furnace \\
Flame1B_21713F & 21713 & With furnace \\
\hline
\end{tabular}




\subsection{Calculation of Theoretical Flame Length}

For calculating the flame length $L_{f}$, Roper's Correlation of circular burner described in a study by Turns [21] is used, which is shown in Eq. (8). Based on Eq. (8), $Q_{F}, T_{\infty}$, and $T_{F}$ are the volumetric flow rate of the fuel, oxidizer stream temperature, and fuel stream temperature, respectively. Variable $S$ represents the molar stoichiometric oxidizer-fuel ratio, calculated by Eq. (9), in which $x$ represents the carbon atom number and $y$ the hydrogen atom number in a hydrocarbon molecule; $\chi_{\mathrm{O}_{2}}$ represents the oxygen's mole concentration in the oxidizer stream and $\chi_{\text {dil }}$ the diluent mole concentration in the fuel stream.

$$
\begin{aligned}
& L_{f}=1330 Q_{F} \frac{\left(T_{\infty} / T_{F}\right)}{\ln (1+1 / S)} \\
& S=\frac{x+y / 4}{\left(\frac{1}{1-\chi_{d i l}}\right) \chi_{O_{2}}}
\end{aligned}
$$

\subsection{CNT Growth Rate Model}

Carbon source interacts with catalyst nanoparticles in the process of CNT generation. The mathematical model that describes this interaction is founded on several assumptions. First, the catalyst particles that fail to undergo surface breakup and become unfavorable for the CNT growth process will not be modeled. Secondly, methane is assumed as the primary carbon source for the growth rate model. Thirdly, a base growth is assumed to ignore the effect of energy gain on the lifting of catalyst particles. Finally, the growth competition between soot particles and other carbon nanomaterials is excluded from the growth rate model.

The current growth rate model consists of six components that elaborate on the basic steps of CNT growth processes. The model is originally proposed by Naha and Puri [22] to outline the time evolution of the surface density of carbon atoms at the catalyst surface as shown by Eq. (10). Carbon atoms collide with catalyst particles under the condition of high temperature as modelled by the first term $F_{c 1}$ in Eq. (10). Some carbon atoms move away from the catalyst surface as modelled by the second term while the rest diffuse through the catalyst particles, indicated by the third term $R_{d, o u t}$ and form stable and critical clusters as represented by the third and fourth term, respectively. When the number of carbon atoms in a cluster reaches a critical value without decomposing back into single atoms, the aggregated carbon atoms are assumed to eventually grow into carbonaceous layer which will encapsulate and deactivate the catalyst particles as modelled by the fifth term. If the critical value is not reached, the aggregated carbon atoms will disintegrate into single atoms and contribute to CNT growth via nucleation [23].

CNT length is determined by Eq. (11) that takes the $n_{1}$ solution from Eq. (10) as input. Variables $a c, C^{*}$, and $D b$, in Eq. (11) are the diameter of a carbon atom, the amount of carbon required for monolayer formation, and the bulk diffusivity of carbon into metal catalyst, respectively. Zainal et al., [24] discusses the entire growth rate model in greater detail.

$$
\begin{aligned}
& \frac{d n_{1}}{d t}=F_{c 1}-\frac{n_{1}}{\tau_{\text {res }}}-R_{d, \text { out }}-\sigma_{x} D_{s} n_{1} n_{x}-(i+1) \sigma_{i} D_{s} n_{1} n_{i}-\Phi_{c 1}\left(\frac{n_{p 1}+n_{p 2}}{\alpha_{m} n_{m} A_{n p}}\right) \\
& L=\frac{1}{a_{c} C^{*}} \frac{\sqrt{D_{b}}}{\pi} \times \int_{0}^{t} \frac{n_{1}}{\sqrt{t}} d t
\end{aligned}
$$




\section{Results and Discussion}

\subsection{Flame Length Validation}

The schematic of the CFD flame simulation is presented in Figure 2(a), in which wire mesh is not included. The flame length is defined as the length from the base of the flame at the burner exit to the tip of the blue flame sheet, as shown in Figure 2(b). The last four cases in Table 2 are utilized for the validation of flame length. Note that the oxygen concentration from Flame $3 A W_{0}$ to Flame $3 D_{0}$ in Table 2 follows an increasing trend of volume concentration, from $19 \%$ to $27 \%$ while the composition of the fuel is kept constant. The results of the theoretical calculation, CFD prediction, and experimental measurements of the flame length for the four cases are tabulated in Table 4. A satisfactory comparison is achieved with a maximum difference of approximately $5 \mathrm{~mm}$, which is $20 \%$ of relative error against experimental data. This finding is supported by the satisfactory comparison of the line-of-sight image of the actual and predicted flame front as shown in Figure 3, in which theoretical flame length is reasonably close to that predicted by CFD simulation. For example, the experimental flame length of Flame $3 A W_{0}$ is about $48 \mathrm{~mm}$ compared to the predicted flame length via CFD, which is approximately $46.1 \mathrm{~mm}$ with approximately $4 \%$ relative error. Discrepancies between experimental measurement and predicted flame length could be attributed to the fluctuation of the flame itself during the experiment.

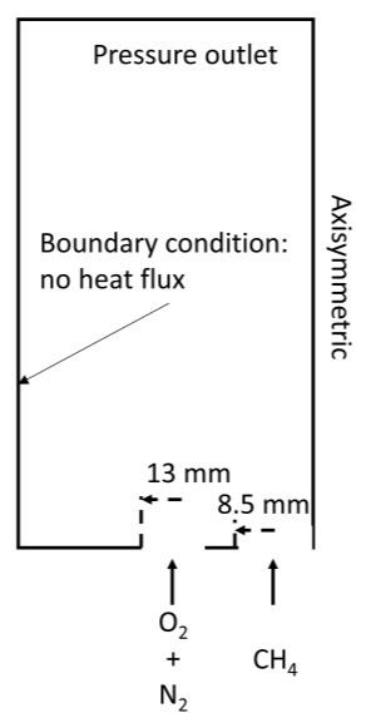

(a)

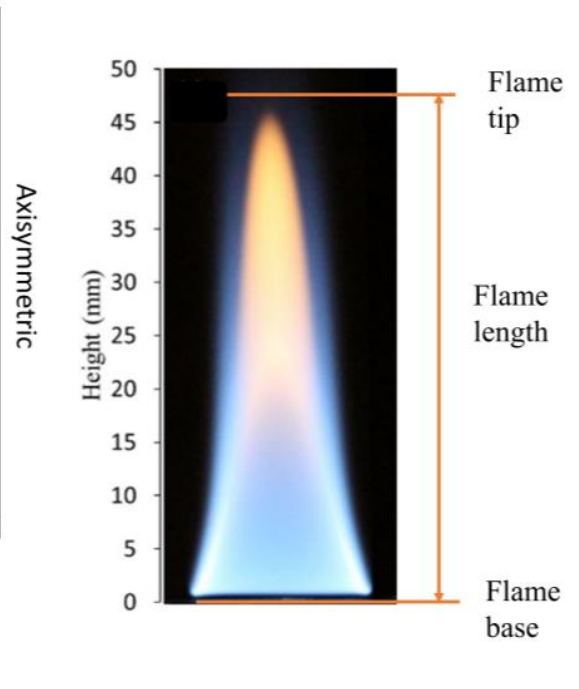

(b)

Fig. 2. Standing flame simulation domain and flame length definition; (a) simulation domain of standing flame, (b) flame length definition 


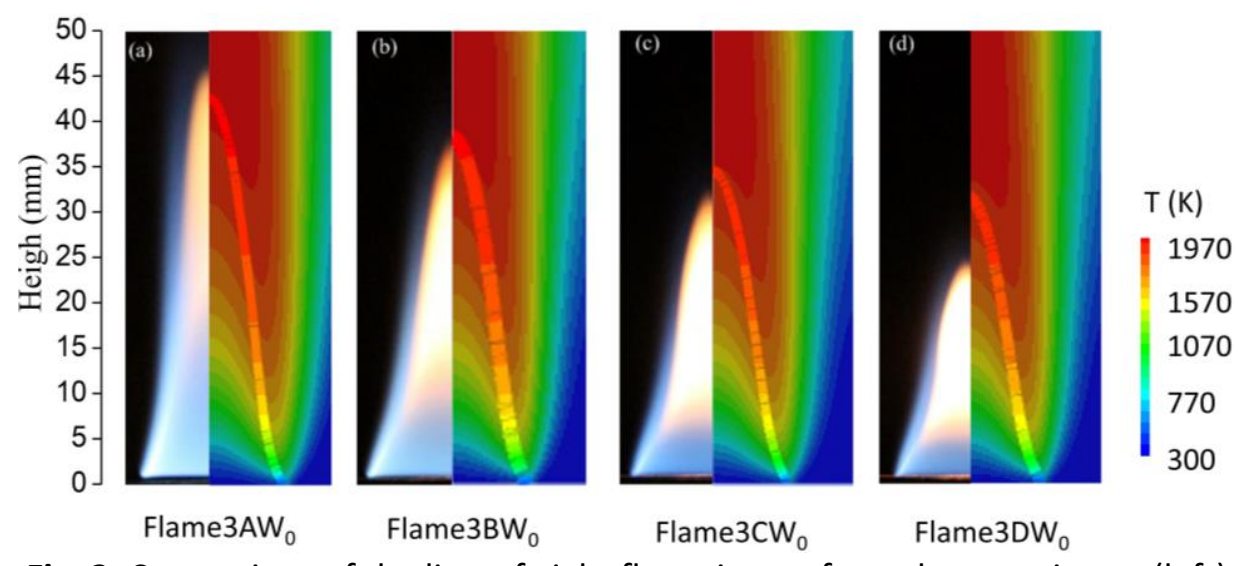

Fig. 3. Comparison of the line-of-sight flame image from the experiment (left) and the reaction zone prediction based on $z_{s t}$ and temperature contour from the present study (right) of the four cases [19]

Table 4

Flame length comparison between theoretical, experimental measurement, and CFD prediction

\begin{tabular}{lllll}
\hline Flame type & $\begin{array}{l}\text { Theoretical value } \\
(\mathrm{mm})[19]\end{array}$ & $\begin{array}{l}\text { Experimental } \\
\text { value }(\mathrm{mm})[19]\end{array}$ & CFD prediction $(\mathrm{mm})$ & $\begin{array}{l}\text { Relative error against } \\
\text { experiment value }\end{array}$ \\
\hline Flame3AW & 45.5 & 48.0 & 46.1 & $4 \%$ \\
Flame3BW & 41.3 & 39.0 & 39.7 & $1.7 \%$ \\
Flame3CW & 35.5 & 32.0 & 35.2 & $10 \%$ \\
Flame3DW $_{0}$ & 32.6 & 25.0 & 30.0 & $20 \%$ \\
\hline
\end{tabular}

\subsection{Flame Shape Validation Under Wire Mesh}

Flame under wire mesh is different from the flame without wire mesh, since wire mesh inhibits the flame from spreading to the downstream region. Flame1BW $W_{0}$ is chosen for flame shape validation, which is represented by the blue flame sheet. The simulation domain used for the flame shape validation includes the wire mesh as shown in Figure 4(a). The present validation compares the flame sheet from CFD simulation to that from the experiment and the predicted temperature contour as shown in Figure 4(b). The blue line is the predicted flame front based on the isoline of stoichiometric mixture fraction $z_{s t}$ with a value of 0.074 .

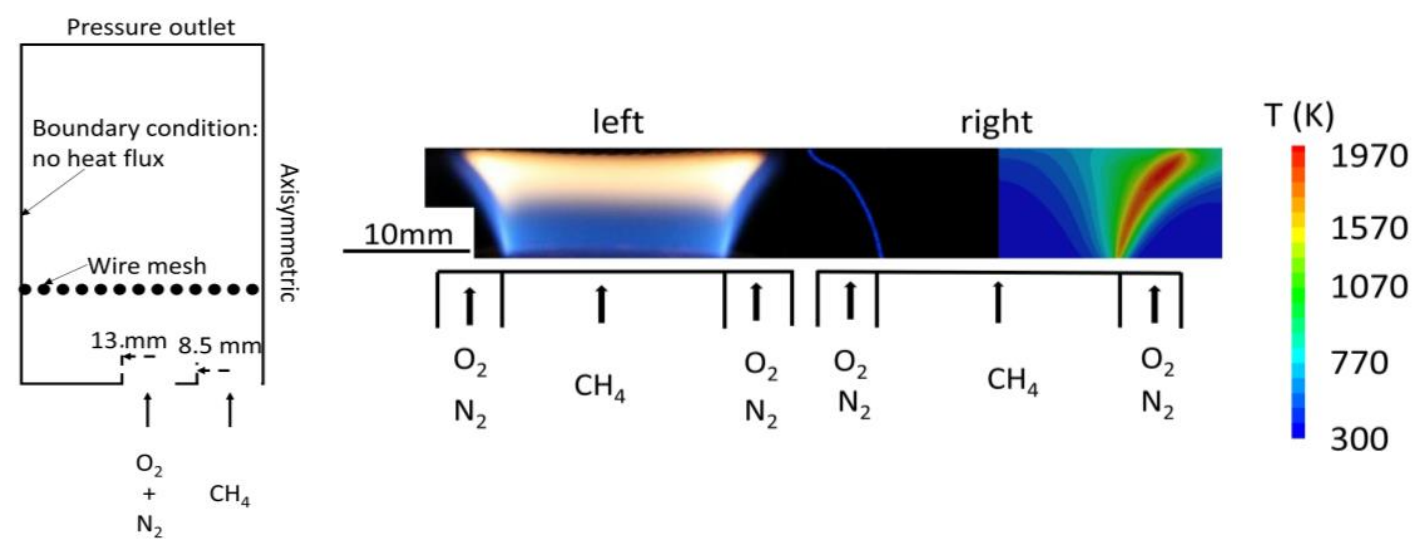

(a)

(b)

Fig. 4. Flame shape validation under wire mesh for Flame1BW $\mathrm{W}_{0}$ (a) Simulation domain of flame under wire mesh without furnace; (b) left: the line-of-sight flame image from the study by Hamzah [19]; right: stoichiometric mixture fraction $z_{s t}$ isoline with the value of 0.074 (blue line) from the present study and the predicted temperature contour 


\subsection{Temperature Profile Validation Under Wire Mesh}

The radial temperature profile of Flame $1 \mathrm{BW}_{0}$ with the presence of wire mesh geometry is presented in Figure 5(a) where the temperature profiles at $11.5 \mathrm{~mm} \mathrm{HAB}$ and $12.5 \mathrm{~mm} \mathrm{HAB}$ are compared with the experimental data. The origin represents the burner centreline, whereas traversing toward the right side of the plot indicates radial distance away from the burner centreline. The maximum flame temperature is about $1500 \mathrm{~K}$, which is lower than methane adiabatic flame temperature of $2300 \mathrm{~K}$ due to the presence of wire mesh. Based on the normal diffusion arrangement, any location less than approximately $9 \mathrm{~mm}$ will be identified as the fuel-rich region and the temperature will be lower than the stoichiometric temperature. The temperature gradually increases along the radial extent outwards due to the rise of oxidizer concentration. Comparison with experimental data at $11.5 \mathrm{~mm} \mathrm{HAB}$ and $12.5 \mathrm{~mm} \mathrm{HAB}$ yields average errors of $12.3 \%$ and $29.4 \%$, respectively. Although the temperature profile of CFD simulation underpredicted the experimental measurements, the general trend of the CFD result conforms to that of the experimental data.

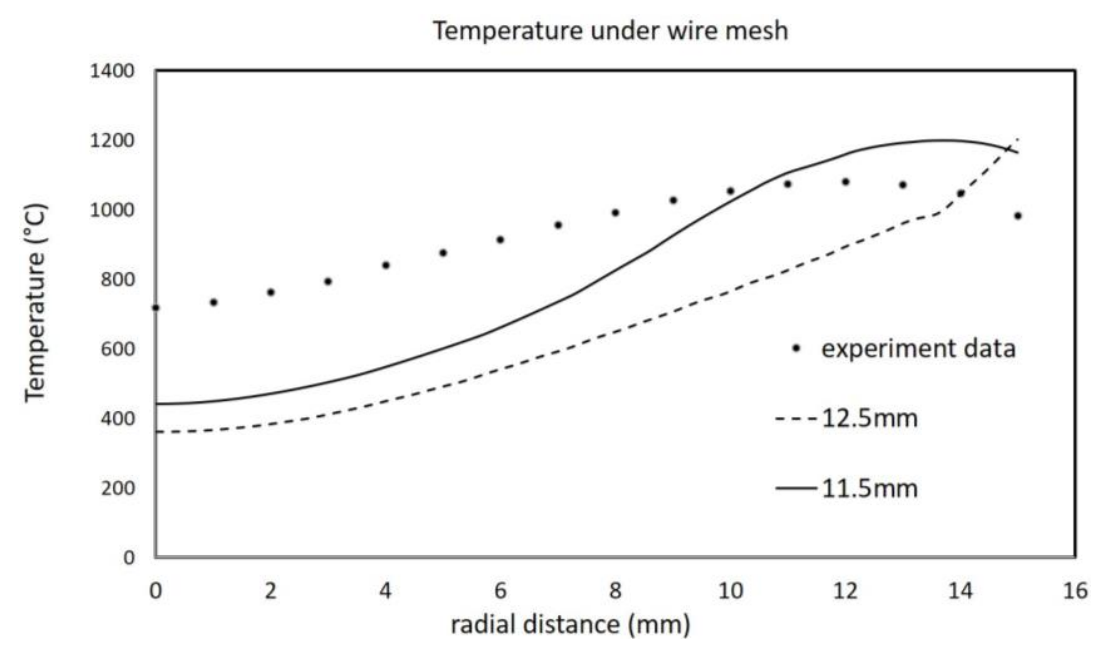

(a)

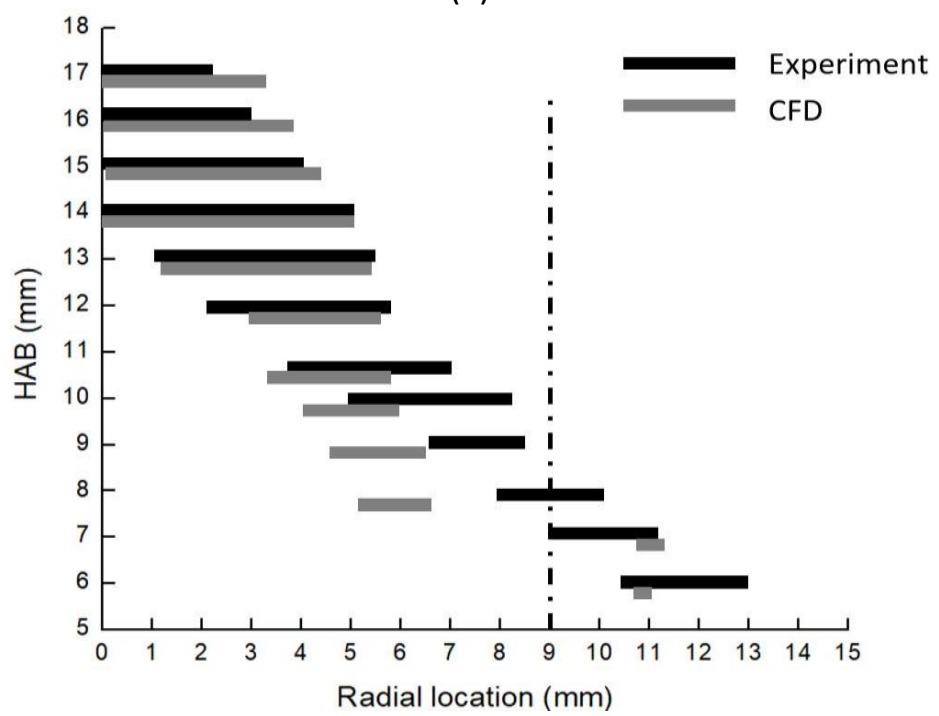

(b)

Fig. 5 Temperature profile under wire mesh at selected distances against experimental data; (b) CNT growth region under wire mesh at different $H A B$ for Flame $1 A W_{0}$. Vertical dashed black line indicates the fuel boundary of the burner. The line at $0 \mathrm{~mm}$ radial location represents the burner centreline 


\subsection{CNT Growth Region Validation of Flame Under Wire Mesh}

The coupled computation of the growth rate model and the flame model is based on the published model by Zainal et al., [11]. A previous experimental study by Hamzah [19] shows that the location of wire mesh will affect the CNT growth region. In the present section, the CNT growth region for Flame $1 \mathrm{AW}_{0}$ is predicted based on 12 locations as shown in Figure 5(b). The black and the grey horizontal bars represent the experimental and computational results of the CNT growth region, respectively. The black dot-dashed vertical line represents the border of the fuel side of the burner. Prediction of the CNT growth region width from $10 \mathrm{~mm}$ HAB to $17 \mathrm{~mm}$ HAB reasonably reflects the experiment results with at least $62 \%$ accuracy. However, when the HAB is lower than $9 \mathrm{~mm}$, the prediction error of growth region size could reach up to $89 \%$, which may happen due to inadequate assumption of $\mathrm{CH}_{4}$ as the sole carbon precursor for CNT growth. Though the assumption is adequate within the low growth temperature region at high $H A B$, the same assumption is seen to be inadequate within the high growth temperature region at high $\mathrm{HAB}$.

\subsection{Modeling of Flame CVD Synthesis with Furnace Boundary Conditions}

To investigate the influence of wall boundary conditions, the simulation domain in Figure $4(a)$ is modified to include a heater to mimic a FECVD furnace as illustrated by Figure 6(a). Here, a wall boundary around the flame is included. Based on the surface area of the wall around the flame, the heater power is transformed to heat flux through the wall as described by Eq. (7). The six heat flux boundary conditions for CFD simulation cases are listed in Table 3. The simulated temperature profile of maximum furnace power is shown in Figure $6(\mathrm{~b})$. When heat flux is increased to $21,713 \mathrm{~W} / \mathrm{m}^{2}$, the temperature of the region within and surrounding the flame increases, either under or above the wire mesh increases.

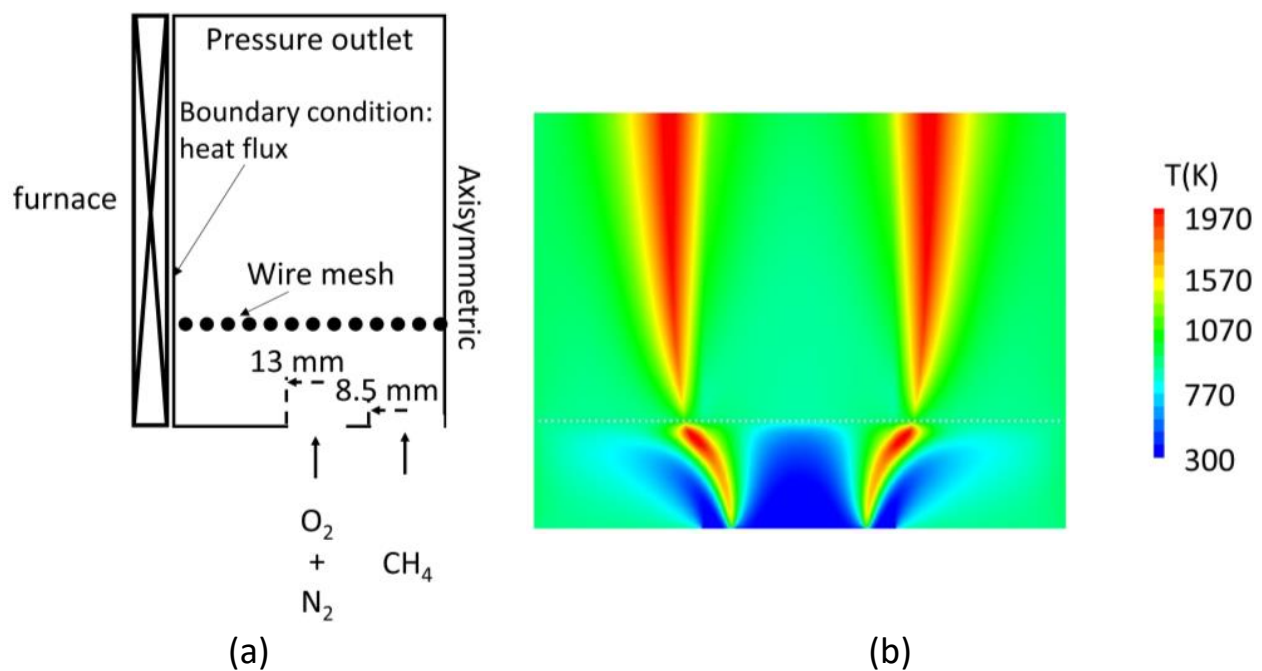

Fig. 6. (a) Schematic of flame under wire mesh with furnace; (b) temperature profile with furnace power of $750 \mathrm{~W}$

\subsection{Effects of Furnace Heating Capacity on CNT Growth}

The predicted CNT length based on the boundary conditions in Table 3 are presented in Figure 7(a). The horizontal axis indicates the burner radial location from the flame centreline. The vertical axis indicates the CNT length predicted by CNT growth rate model. The range of the predicted CNT 
growth region lies between the burner centerline and a radial distance of $13.5 \mathrm{~mm}$. Despite the varying heat flux that alters temperature distribution around the wire mesh, all six cases exhibit a similar pattern of CNT length with respect to the radial location. Based on Figure 6(a), the CNT length gradually increases from the centerline and reaches a peak, which also happens to be the location of the flame sheet. The improvement of CNT lengths with increased heater power indicates the benefit of employing the FECVD in the CNT synthesis furnace. When the furnace power is raised, the higher incoming heat flux through the wall provides wider regions with uniform heat that is conducive for CNT growth and enhanced the synthesized CNT length.

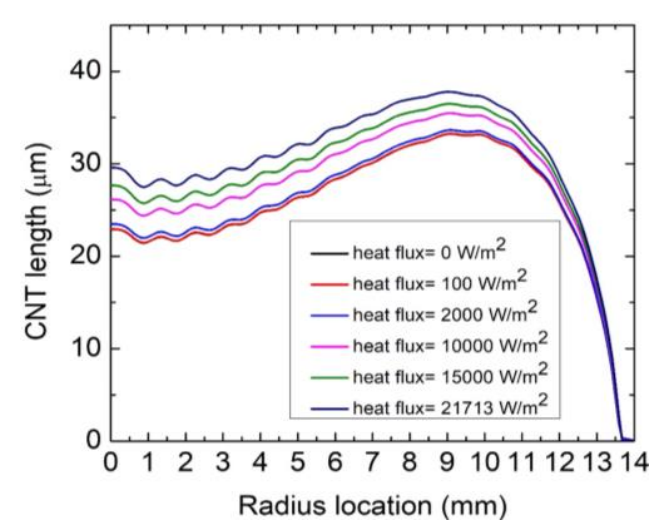

(a)

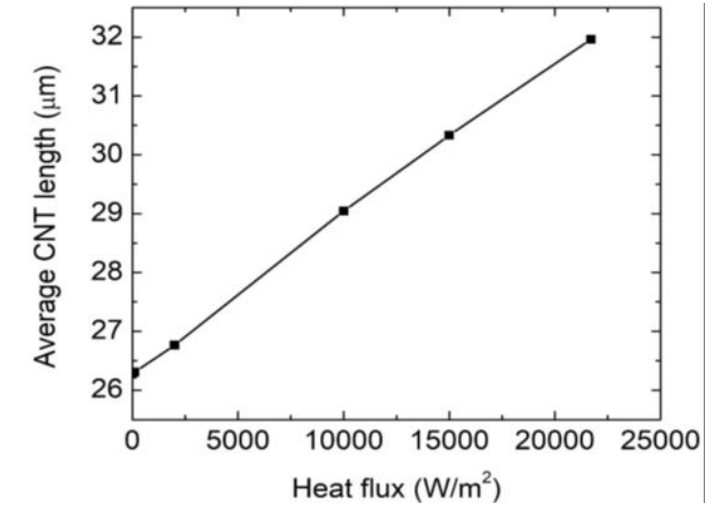

(b)

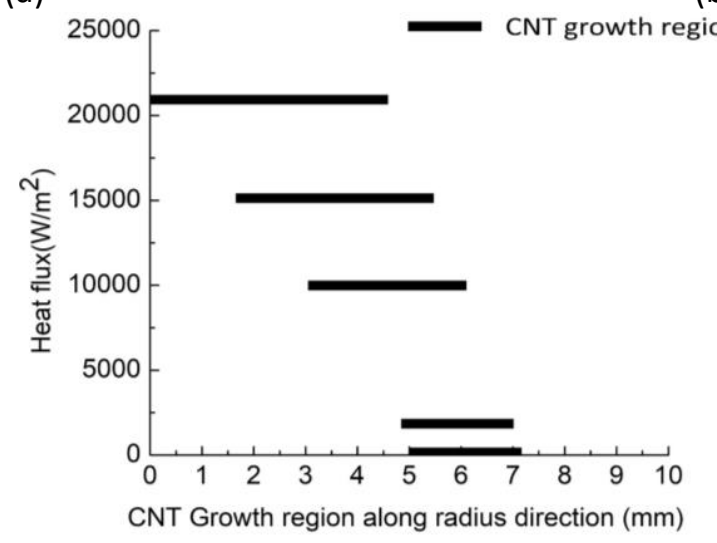

(c)

Fig. 7. Prediction of the (a) overall CNT length; (b) average CNT length for varying heat flux; (c) CNT growth region prediction with furnace at different heat flux (HAB $=13$ $\mathrm{mm}$ ). The line at radial distance $=0$ is the burner's centreline

When the heat flux is raised from 0 to $21,713 \mathrm{~W} / \mathrm{m}^{2}$, the predicted CNT length increased by approximately $10 \mu \mathrm{m}$, which indicates a $50 \%$ improvement in growth compared to CNT growth without the furnace. Based on Figure 7(b), it is observed that the average CNT length also increases with heat flux. The average CNT length at a heat flux of $0 \mathrm{~W} / \mathrm{m}^{2}$ is $26 \mu \mathrm{m}$. This value increases to 31 $\mu \mathrm{m}$ at the maximum heater power of $750 \mathrm{~W}$. To estimate the CNT growth regions for each case, the threshold values are selected based on the average CNT length where values of the lower threshold $L_{\min }$ and upper threshold $L_{\max }$ are $26 \mu \mathrm{m}$ and $31 \mu \mathrm{m}$, respectively.

The predicted CNT growth region for different heat power ratings is presented in Figure $7(\mathrm{c})$ as indicated by the black horizontal bar. The horizontal axis represents the burner radial distance whereas the vertical axis denotes the heat flux through the furnace wall which also implies the heater power. The growth region widens when heat flux increases, and the maximum growth region is 
obtained when heat flux reaches $21,713 \mathrm{~W} / \mathrm{m}^{2}$. It is also observed that the CNT growth region shifts toward the burner centerline with increasing heater power.

\subsection{Effects of Flame Structure on CNT Growth Region with Different Heat Flux}

In the present study, the flame structures are produced based on the flame temperature profiles and mass concentrations of several combustion products. The temperature and mass fraction of species are extracted at $12.5 \mathrm{~mm} \mathrm{HAB}$, which is the location right below the wire mesh where CNT growth is sampled [19]. Two variants of the flame structure are produced, one with respect to the radial space and the other with respect to mixture fraction space as shown in Figure 8 . Based on Figure 8, the left and the right axes represent the flame temperature and the species mass fraction, respectively. The horizontal axis of Figure $8(\mathrm{a})$ and Figure $8(\mathrm{c})$ represents the burner radial location whereas that of Figure $8(\mathrm{~b})$ and Figure $8(\mathrm{~d})$ the mixture fraction. Flame structure analysis is carried out at a heat flux of 0 and $21,713 \mathrm{~W} / \mathrm{m}^{2}$.

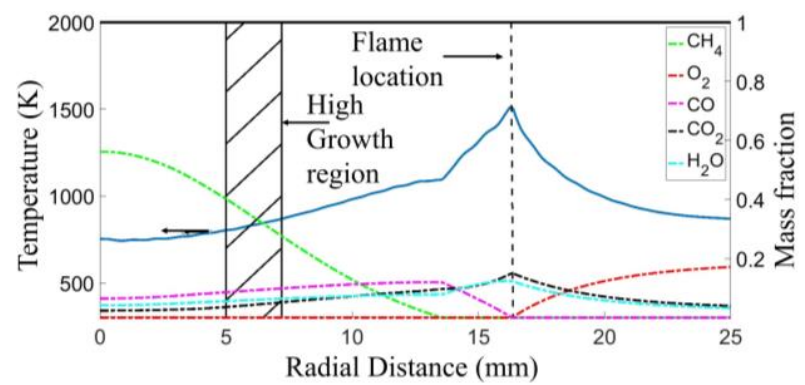

(a) Heat flux $=0 \mathrm{~W} / \mathrm{m}^{2}$

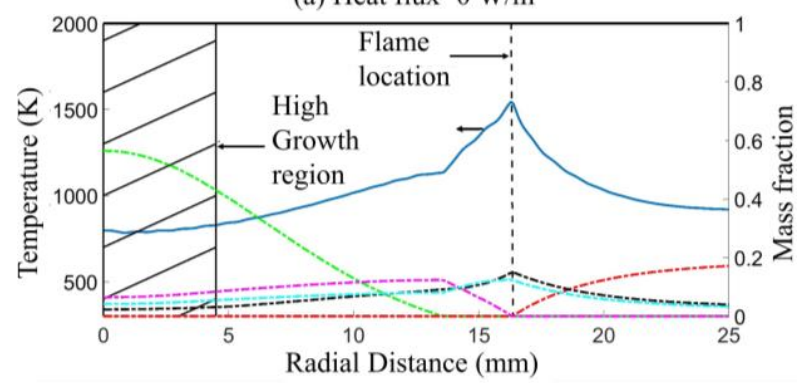

(c) Heat flux $=21713 \mathrm{~W} / \mathrm{m}^{2}$

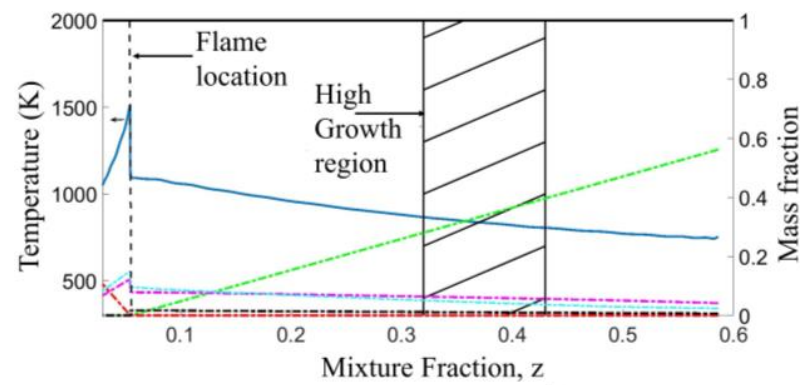

(b) Heat flux $=0 \mathrm{~W} / \mathrm{m}^{2}$

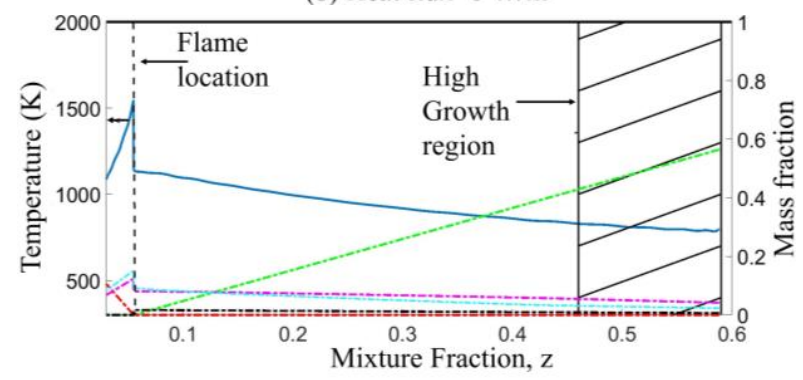

(d) Heat flux $=21713 \mathrm{~W} / \mathrm{m}^{2}$

Fig. 8. Flame structure based on (a), (c) radial space and (b), (d) mixture fraction space for Flame1BW

Referring to Figure 8, the flame location which is the reaction zone is indicated by the location of maximum temperature. The growth region is successfully predicted right outside of the reaction zone where high temperature and carbon precursor concentration are found. As expected for normal diffusion flames with excess fuel, oxygen is fully consumed beyond the reaction zone to prevent undesirable oxidation of catalyst during the CNT growth. The inclusion of a heater not only enlarges the CNT growth region, but also causes the CNT growth region to be shifted toward the center of the burner, as observed from Figure 8(a) and Figure 8(c). Note that the flame locations in Figure 8(a) and Figure $8(c)$ are not affected by the furnace, since flame sheet is determined mainly by the local mixture fraction. Figure $8(\mathrm{~b})$ shows that the high growth region for the case of zero heat flux lies within the mixture fraction range of approximately 0.32 to 0.43 . For the case of heat flux of 21,713 $\mathrm{W} / \mathrm{m}^{2}$, the CNT growth region with high growth occurring at the mixture fraction range of 0.46 to 0.59 , as shown in Figure $8(\mathrm{~d})$. Note that, just like the growth region prediction in radial space, the growth region in the mixture fraction space in Figure $8(b)$ is also shifted toward the centerline as shown in Figure 8(d). 
It is interesting to note that in Figure $8(\mathrm{a})$ and Figure $8(\mathrm{c})$, the changes in temperatures along the radial direction are not smooth; meanwhile the temperature in Figure $8(\mathrm{~b})$ and Figure $8(\mathrm{~d})$ experiences a steep drop at a mixture fraction of approximately 0.06 . The occurrence of this phenomenon can be attributed to the effect of wire mesh placement inside the flame, which dramatically alters the flame shape and flow field and consequently affects and the temperature profile.

\subsection{Effects of Oxidizer Concentration on CNT Growth}

In the present study, the composition of the air stream is varied by specifying four different oxygen concentrations. This parametric study is done with the presence of a heater with constant heat flux of $21,713 \mathrm{~W} / \mathrm{m}^{2}$. The oxidizer stream compositions for all four cases are listed in Table 2 , ranging from $19 \%$ to $27 \% \mathrm{O}_{2}$, while the methane fuel concentration is fixed at $100 \%$. Figure $9(\mathrm{a})$ demonstrates the temperature profile and carbon source concentration in physical space at $12.5 \mathrm{~mm}$ $\mathrm{HAB}$. The maximum flame temperature for the case with $27 \% \mathrm{O}_{2}$ is approximately 1.2 times the maximum temperature of the case of $19 \% \mathrm{O}_{2}$ because the stoichiometric value increases with the oxygen concentration which leads to a higher maximum temperature. This finding is similar to a previous modeling study by Zainal et al., [11] that investigated the effect of oxygen concentration from $25 \%$ to $35 \%$ in an inverse diffusion flame. For the normal diffusion flame under wire mesh with external heating, increasing oxygen concentration also expands the CNT growth region.

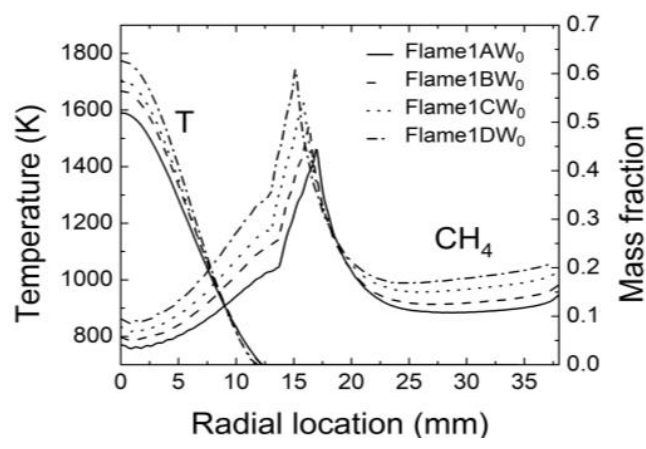

(a)

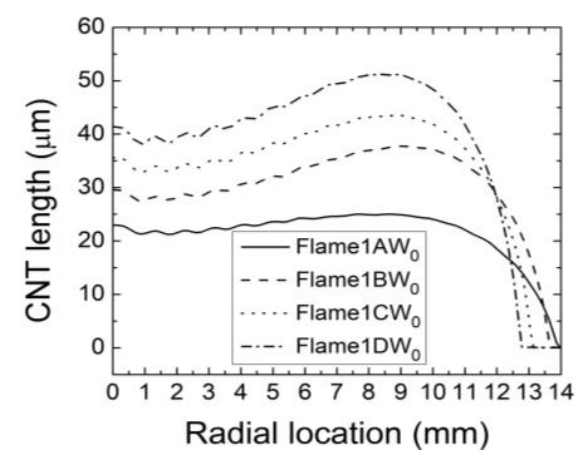

(b)

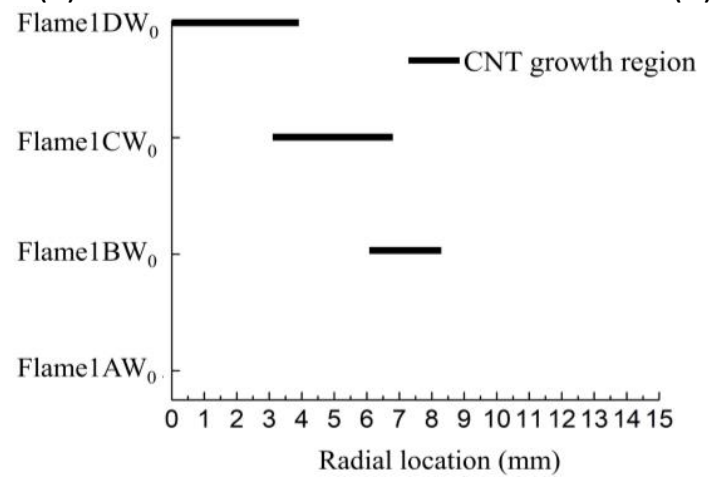

(c)

Fig. 9. (a) Flame structures of flame under wire mesh for 4 different oxygen concentrations $\left(19 \% \mathrm{O}_{2}, 21 \% \mathrm{O}_{2}, 24 \% \mathrm{O}_{2}\right.$, and $\left.27 \% \mathrm{O}_{2}\right)$ at $12.5 \mathrm{~mm} \mathrm{HAB}$; (b) CNT length prediction for different oxidizer concentrations; (c) CNT growth region prediction with furnace of different flames. Zero radial distance represents the burner's centreline 
Figure 9(b) shows that the CNT length increases with inlet oxygen concentration. The maximum CNT length produced in Flame1DW 0 is about $52 \mu \mathrm{m}$. It is interesting to note that the bell-shaped curve of the predicted CNT length slightly narrows down from the radial distance of $14 \mathrm{~mm}$ to 13 $\mathrm{mm}$. The location of maximum CNT length for each flame is approximately $9 \mathrm{~mm}$ away from the centerline. This condition implies that the location of the maximum temperature does not change across the four flames of varying oxygen concentration. The increase in heat release at higher oxygen concentration provides a larger hot region that is favorable for CNT production. This process expands the CNT growth region by keeping the carbon source concentration constant.

By employing the same threshold percentage mentioned earlier, the values of $L_{\min }$ and $L_{\max }$ for the present parametric study are $34 \mu \mathrm{m}$ and $41 \mu \mathrm{m}$ respectively. Based on this threshold, the CNT growth regions for Flame1AWo, Flame1BWo, Flame1CW0, and Flame1DWo are determined as shown in Figure 9(c). Note that for the selected threshold value, no high CNT growth region is predicted for Flame1AWo. However, increasing the oxygen concentration is observed to slightly increase the CNT production by approximately 5\% where the CNT growth region shifts closer to the burner centerline.

\subsection{Effects of Flame Structure on CNT Growth Region at Varying Oxidizer Concentration}

Since Flame $1 \mathrm{AW}_{0}$ does not show a high growth region based on the threshold criteria described earlier, its flame structure is not included in the discussion. Figure 10 shows the physical-based and the mixture fraction-based flame structures for the flame under a wire mesh at $12.5 \mathrm{~mm} \mathrm{HAB}$ with varying oxidizer concentrations. Although the published work by Hamzah et al., [15] analyzed a wide range of growth locations from $6 \mathrm{~mm}$ to $17 \mathrm{~mm} \mathrm{HAB}$, the present study focuses on $12.5 \mathrm{~mm} \mathrm{HAB}$ with different oxidizers to study the effects of oxygen concentration on CNT growth region. When the oxygen concentration increases from $21 \%$ to $27 \%$, the stoichiometric mixture fraction of these four flames increases from 0.05 up to 0.0691 as shown in Table 2.

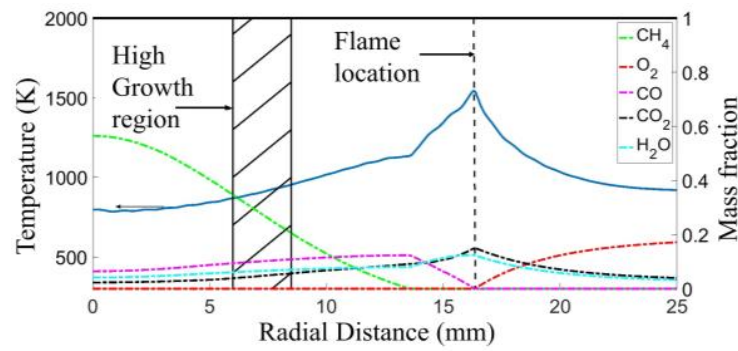

(a) Flame $1 \mathrm{BW}_{0}, 21 \% \mathrm{O}_{2}$

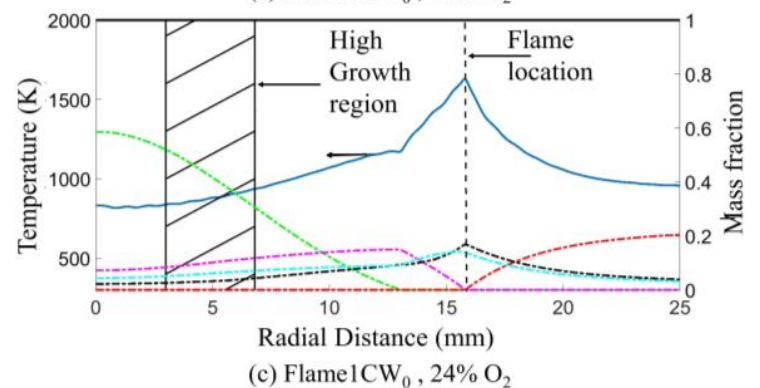

(c) Flame $1 \mathrm{CW}_{0}, 24 \% \mathrm{O}_{2}$

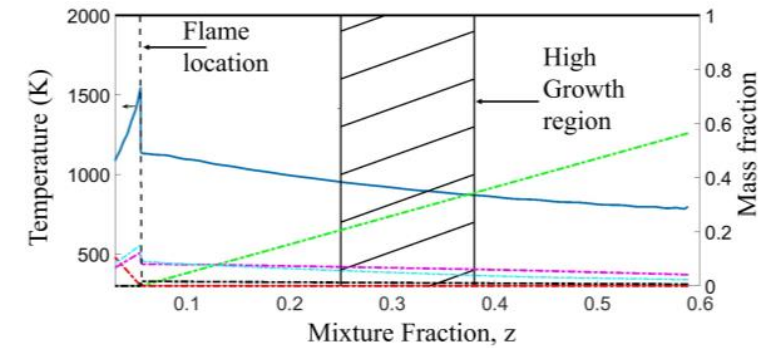

(b) FlamelBW $\mathrm{BW}_{0}, 21 \% \mathrm{O}_{2}$

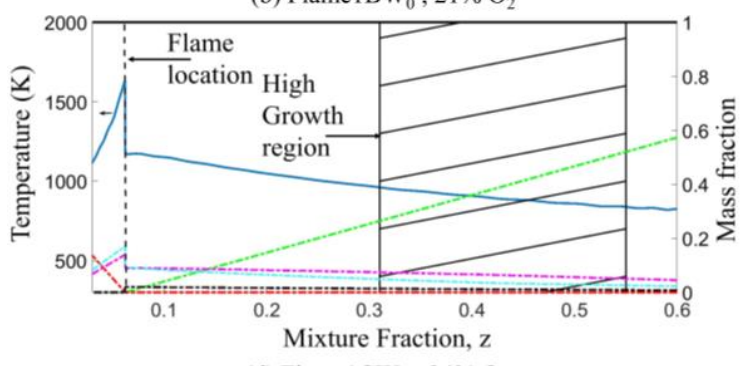

(d) Flame $1 \mathrm{CW}_{0}, 24 \% \mathrm{O}_{2}$ 


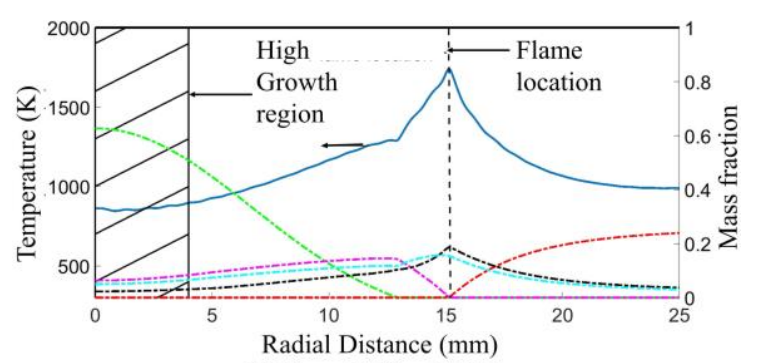

(e) Flame $1 \mathrm{DW}, 27 \% \mathrm{O}_{2}$

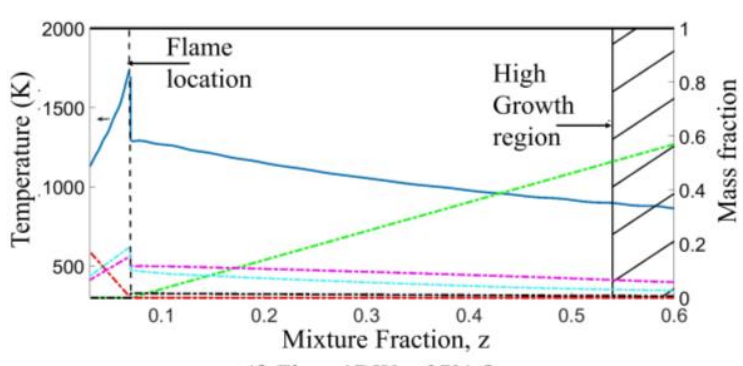

(f) Flame $1 \mathrm{DW}_{0}, 27 \% \mathrm{O}_{2}$

Fig. 10. Flame structure based on radial location for three flames under wire mesh with heat flux at the furnace wall of $21,713 \mathrm{~W} / \mathrm{m}^{2}$

Figure 10(a), Figure 10(c), and Figure 10(e) show the location of the high CNT growth region in the radial space. The growth region is observed to shift closer toward the centerline as the oxygen concentration at the inlet increases. A similar trend of the CNT growth region in the mixture fraction space is observed as shown by Figure 10(b), Figure 10(d), and Figure 10(f). CNT growth region expands from $0 \mathrm{~mm}$ to approximately $4 \mathrm{~mm}$ as the initial oxygen concentration increases from $19 \%$ to $27 \%$. For the three cases, the flame front is located at approximately $14 \mathrm{~mm}$ in the radial space, which is consistent with the characteristics of diffusion flame (the flame front location is not influenced by the air to fuel ratio) reported by Zhang et al., [25].

Figure 10(b), Figure 10(d), and Figure 10(f) show that the high CNT growth region experiences a twofold expansion as oxygen concentration increases from $21 \%$ to $24 \%$ and then drops back to its previous state as initial oxygen concentration increases to $27 \%$. As mentioned earlier, the abundance of oxygen assists in more heat release and creates a larger favorable environment for CNT production. Effect of abundance of high temperature region on improved yield and qualities of CNT has been observed by previous flame synthesis study by Zhang et al., [17]. Nonetheless, too much excess of oxygen is assumed to consume the potential carbon source or deactivate the catalyst particles and reduces CNT production. The limitation of the positive effect of oxygen can be inferred from a recent study that demonstrated expansion of CNT growth in inverse diffusion flame when oxygen concentration was raised from $15 \%$ to $30 \%$ and reduction in CNT growth when the oxygen is further increased to $40 \%$ [18].

Referring to the physical space-based flame structures in Figure 10(a), Figure 10(c), and Figure 10(e), the radial location that marks complete consumption of the $\mathrm{CH}_{4}$ and $\mathrm{CO}$ coincides with the maximum temperature. The CNT growth region is predicted right outside of the reaction zone toward the flame centreline where favorable high temperature and carbon precursor concentration are found. As expected from a normal diffusion flame with excess fuel, the oxygen is entirely consumed beyond the reaction zone to prevent undesirable oxidation of catalyst during the CNT growth. Interestingly, Figure 10(e) shows that increasing the oxidizer concentration not only enlarges the CNT growth region, but also pushes the CNT growth region toward the centerline. Note that the flame locations in Figure 10(a), Figure 10(c), and Figure 10(e) are not affected by the presence of the heater with maximum power rate. Figure 10 (b) shows that the high growth region lies in a mixture fraction range of approximately 0.25 to 0.4 for Flame1BW 0 . The mixture fraction range for the CNT growth region enlarges for Flame1CW 0 with a range of 0.3 to 0.55 as shown in Figure 10 (d). However, the high growth region shrinks for Flame1DW 0 with a mixture fraction range of 0.55 to 0.65 as shown in Figure 10(f). 


\section{Conclusions}

A comprehensive validation is carried out at the flame scale and the particle scale based on Flame $1 \mathrm{BW}_{0}$, which operates at $100 \% \mathrm{CH}_{4}$ and $21 \% \mathrm{O}_{2}$. At the flame scale, the predicted flame length for flame with varying stoichiometric mixture fraction are compared with the experimental study. The predicted flame shape that is obtained from CFD simulation based on $z_{s t}$ is compared with the experimental flame image and shows excellent agreement. The predicted radial temperature profile is compared with experimental data at $11.5 \mathrm{~mm} \mathrm{HAB}$ with an average error below $15 \%$. The CNT growth region is compared at multiple HABs and shows at least $62 \%$ accuracy in terms of growth region magnitude when $\mathrm{HABs}$ are greater than $9 \mathrm{~mm}$.

Six boundary conditions that emulate different furnace heating powers are imposed on the baseline model to investigate the CNT growth in a furnace environment. The effects of the heat flux on the temperature field in the flame and the CNT growth region are investigated. A preheated furnace plays a significant role in CNT production of a flame-enhanced synthesis compared with a pure flame-based synthesis; when the heat flux at the furnace wall is increased, the CNT length and CNT growth region are observed to increase.

A flame structure analysis is carried out for the case where the furnace operates in the absence of heating and for the case where the heater is turned on at high power. Flame structure analysis in the physical and the mixture fraction spaces demonstrate that increased heater power causes CNT growth region to enlarge and shift toward the center of the furnace. The effect of oxygen concentration on the furnace temperature and CNT growth in a flame-assisted furnace environment is also investigated. Three concentrations of $21 \%, 24 \%$, and $27 \% \mathrm{O}_{2}$ are analyzed while keeping the heat flux at the furnace wall fixed at the maximum furnace power (heat flux of $21,713 \mathrm{~W} / \mathrm{m}^{2}$ ). By increasing the oxidizer concentration, CNT growth in terms of length and high yield region is observed to improve. Analysis of the mixture fraction-based flame structure shows that when the inlet oxygen concentration is raised from $21 \%$ to $24 \%$, the CNT growth region experiences a twofold expansion. However, increasing the oxygen level to $27 \%$ causes the growth region to shrink back to its earlier state as $21 \% \mathrm{O}_{2}$ which is caused by the depletion of carbon source due to overconsumption by excess oxygen.

\section{Acknowledgement}

This research was supported by Ministry of Education (MOE) through the Fundamental Research Grant Scheme (FRGS/1/2020/TK0/UTM/02/54) with cost center number R.J130000.7851.5F377 and (FRGS/1/2019/TK05/UTM/02/8) with cost center number R.J130000.7851.5F182. The research is also funded by Universiti Teknologi Malaysia (UTM) through UTM Fundamental Research (UTMFR: PY/2019/01657) grant with cost center number Q.J130 $000.2551 .21 \mathrm{H} 10$. The Department of Digital Services (UTM Digital) in Universiti Teknologi Malaysia has provided high-performance computer (HPC) and online technical support.

\section{References}

[1] Halim, Nur Fazlin Che, and Nor Azwadi Che Sidik. "Nanorefrigerants: A Review on Thermophysical Properties and Their Heat Transfer Performance." Journal of Advanced Research in Applied Sciences and Engineering Technology 20, no. 1 (2020): 42-50. https://doi.org/10.37934/araset.20.1.4250

[2] Hamzah, N., MF Mohd Yasin, MZ Mohd Yusop, A. Saat, and NA Mohd Subha. "Rapid production of carbon nanotubes: a review on advancement in growth control and morphology manipulations of flame synthesis." Journal of Materials Chemistry A 5, no. 48 (2017): 25144-25170. https://doi.org/10.1039/C7TA08668G

[3] Manawi, Yehia M., Ayman Samara, Tareq Al-Ansari, and Muataz A. Atieh. "A review of carbon nanomaterials' synthesis via the chemical vapor deposition (CVD) method." Materials 11, no. 5 (2018): 822. https://doi.org/10.3390/ma11050822 
[4] Yamamoto, Yuna, Shuhei Inoue, and Yukihiko Matsumura. "Thermal decomposition products of various carbon sources in chemical vapor deposition synthesis of carbon nanotube." Diamond and Related Materials 75 (2017): 15. https://doi.org/10.1016/i.diamond.2016.11.017

[5] Li, Shuiqing, Yihua Ren, Pratim Biswas, and D. Tse Stephen. "Flame aerosol synthesis of nanostructured materials and functional devices: Processing, modeling, and diagnostics." Progress in Energy and Combustion Science 55 (2016): 1-59. https://doi.org/10.1016/i.pecs.2016.04.002

[6] Zainal, Muhammad Thalhah, Mohd Fairus Mohd Yasin, and Mazlan Abdul Wahid. "Optimizing flame synthesis of carbon nanotubes: experimental and modelling perspectives." Jurnal Teknologi 78, no. 8-4 (2016): $133-145$. https://doi.org/10.11113/it.v78.9595

[7] Naha, Sayangdev, Swarnendu Sen, Anindya K. De, and Ishwar K. Puri. "A detailed model for the flame synthesis of carbon nanotubes and nanofibers." Proceedings of the Combustion Institute 31, no. 2 (2007): 1821-1829. https://doi.org/10.1016/i.proci.2006.07.224

[8] Suzuki, S., and S. Mori. "Synthesis of carbon nanotubes from biofuel as a carbon source through a diesel engine." Diamond and Related Materials 82 (2018): 79-86. https://doi.org/10.1016/j.diamond.2018.01.003

[9] Hamzah, N., M. F. Mohd Yasin, M. Z. Mohd Yusop, M. T. Zainal, and M. A. F. Rosli. "Identification of CNT growth region and optimum time for catalyst oxidation: experimental and modelling studies of flame synthesis." Evergreen Joint Journal of Novel Carbon Resource Sciences \& Green Asia Strategy 6, no. 1 (2019): 85-91. https://doi.org/10.5109/2328409

[10] Okada, Shohei, Hisashi Sugime, Kei Hasegawa, Toshio Osawa, Shohei Kataoka, Hiroki Sugiura, and Suguru Noda. "Flame-assisted chemical vapor deposition for continuous gas-phase synthesis of 1-nm-diameter single-wall carbon nanotubes." Carbon 138 (2018): 1-7. https://doi.org/10.1016/i.carbon.2018.05.060

[11] Zainal, M. T., M. F. Mohd Yasin, M. Abdul Wahid, and M. Mohd Sies. "A flame structure approach for controlling carbon nanotube growth in flame synthesis." Combustion Science and Technology 193, no. 8 (2021): 1326-1342. https://doi.org/10.1080/00102202.2019.1694518

[12] Escudero, F., A. Fuentes, R. Demarco, J-L. Consalvi, F. Liu, J. C. Elicer-Cortés, and C. Fernandez-Pello. "Effects of oxygen index on soot production and temperature in an ethylene inverse diffusion flame." Experimental Thermal and Fluid Science 73 (2016): 101-108. https://doi.org/10.1016/i.expthermflusci.2015.09.029

[13] Li, Sen. "Modeling of pressure effects on flame structure and soot formation of n-heptane/air co-flow laminar flames by skeletal reaction mechanism." Applied Thermal Engineering 106 (2016): 1458-1465. https://doi.org/10.1016/i.applthermaleng.2016.03.006

[14] Yan, Weijie, Dongmei Chen, Zuomei Yang, Enyu Yan, and Peitao Zhao. "Measurement of soot volume fraction and temperature for oxygen-enriched ethylene combustion based on flame image processing." Energies 10, no. 6 (2017): 750. https://doi.org/10.3390/en10060750

[15] Hamzah, Norikhwan, Mohd Fairus Mohd Yasin, Mohd Zamri Mohd Yusop, Muhammad Aniq Shazni Mohammad Haniff, Mohd Faizal Hasan, Khairul Fikri Tamrin, and Nurul Adilla Mohd Subha. "Effect of fuel and oxygen concentration toward catalyst encapsulation in water-assisted flame synthesis of carbon nanotubes." Combustion and Flame 220 (2020): 272-287. https://doi.org/10.1016/j.combustflame.2020.07.007

[16] Hou, Shuhn-Shyurng, and Wei-Cheng Huang. "Influence of oxygen concentration, fuel composition, and strain rate on synthesis of carbon nanomaterials." Journal of Nanoparticle Research 17, no. 2 (2015): 1-11. https://doi.org/10.1007/s11051-015-2879-7

[17] Zhang, Cen, Bo Tian, Cheng Tung Chong, Boning Ding, Luming Fan, Xin Chang, and Simone Hochgreb. "Synthesis of single-walled carbon nanotubes in rich hydrogen/air flames." Materials Chemistry and Physics 254 (2020): 123479. https://doi.org/10.1016/i.matchemphys.2020.123479

[18] M. T. Zainal, "Multi-scale modelling on the effects of flame parameters on carbon nanotube growth in nonpremixed flames," 2021.

[19] N. Hamzah, "Analysis of Carbon Nanotube Synthesis in Methane Diffusion Flame," 2020.

[20] Medhat, Moataz, Mohamed Yehia, Adel Khalil, Miguel C. Franco, and Rodolfo C. Rocha. "A Numerical Prediction of Stabilized Turbulent Partially Premixed Flames Using Ammonia/Hydrogen Mixture." Journal of Advanced Research in Fluid Mechanics and Thermal Sciences 87, no. 3 (2021): 113-133. https://doi.org/10.37934/arfmts.87.3.113133

[21] Turns, Stephen R. An Introduction to Combustion: Concepts and Applications. 3rd Edition. New York, NY, USA: McGraw-Hill Companies, 2012.

[22] Naha, Sayangdev, and Ishwar K. Puri. "A model for catalytic growth of carbon nanotubes." Journal of Physics D: Applied Physics 41, no. 6 (2008): 065304. https://doi.org/10.1088/0022-3727/41/6/065304

[23] Zainal, Muhammad Thalhah, Mohd Fairus Mohd Yasin, Muhammad Abid Ira Irawan, Muhammad Faizullizam Roslan, Norikhwan Hamzah, and Mohd Zamri Mohd Yusop. "Investigation on the deactivation of cobalt and iron catalysts in catalytic growth of carbon nanotube using a growth rate model." Journal of Advanced Research in Materials Science 51, no. 1 (2018): 11-22. 
[24] Zainal, M. T., MF Mohd Yasin, and M. Abdul Wahid. "Investigation of the coupled effects of temperature and partial pressure on catalytic growth of carbon nanotubes using a modified growth rate model." Materials Research Express 3, no. 10 (2016): 105040. https://doi.org/10.1088/2053-1591/3/10/105040

[25] Zhang, Ting, Qinghua Guo, Xudong Song, Zhijie Zhou, and Guangsuo Yu. "The chemiluminescence and structure properties of normal/inverse diffusion Flames." Journal of Spectroscopy $2013 \quad$ (2013). https://doi.org/10.1155/2013/304717 